\title{
IdeAs
}

Idées d'Amériques

$6 \mid 2015$

Migrer dans les Amériques

\section{Migrar en las Américas}

Migrer dans les Amériques

Migrating in the Americas

Françoise Lestage y Paul Schor

Traductor: Marta Gómez

\section{CpenEdition}

\section{Journals}

\section{Edición electrónica}

URL: https://journals.openedition.org/ideas/3091

DOI: 10.4000/ideas.3091

ISSN: 1950-5701

Este artículo es una traducción de:

Migrer dans les Amériques - URL : https://journals.openedition.org/ideas/1038 [

Otras traducciones del artículo:

Migrating in the Americas - URL : https://journals.openedition.org/ideas/3084 [en]

Migrar nas Américas - URL : https://journals.openedition.org/ideas/4728 [pt]

\section{Editor}

Institut des Amériques

Referencia electrónica

Françoise Lestage y Paul Schor, «Migrar en las Américas», IdeAs [En línea], 6 | 2015, Publicado el 19 octubre 2015, consultado el 18 octubre 2022. URL: http://journals.openedition.org/ideas/3091 ; DOI: https://doi.org/10.4000/ideas.3091

Este documento fue generado automáticamente el 18 octubre 2022

\section{(c) $($ i) $(9)$}

Creative Commons - Atribución-NoComercial-SinDerivadas 4.0 Internacional - CC BY-NC-ND 4.0 https://creativecommons.org/licenses/by-nc-nd/4.0/ 


\title{
Migrar en las Américas
}

\author{
Migrer dans les Amériques \\ Migrating in the Americas \\ Françoise Lestage y Paul Schor \\ Tradución : Marta Gómez
}

1 El presente dossier, centrado en la migración en las Américas, está dedicado a la memoria de Aristide Zolberg (1931-2013), cuyos trabajos de deconstrucción del mito de Estados Unidos, tierra de migrantes ${ }^{1}$, son una importante aportación al estudio de las migraciones y la construcción nacional. Zolberg participó además en el coloquio «La migration en héritage» (La migración en herencia), celebrado en París en junio de 2012, en el que se debatieron algunos de los textos incluidos en este dossier ${ }^{2}$.

2 La migración es un fenómeno global y las Américas mantienen una relación especial con ella, ya que la misma palabra «migración» es contemporánea de los primeros movimientos transatlánticos posteriores al «descubrimiento» de América a finales del siglo XV. Las Américas -cuya etiqueta identitaria de «Nuevo Mundo» ya da cuenta de la temporalidad en que transcurren las experiencias migratorias- han vivido desde entonces múltiples oleadas de flujos migratorios, transoceánicos e intramericanos, que han hecho del continente el lugar de encuentro, instalación y confrontación, pero también de intercambio, de poblaciones venidas de distintas partes del mundo. A escala del continente, es preciso reconocer «la larga duración» del fenómeno migratorio, por no hablar de su carácter constitutivo. América y su población, en su mayoría oriunda de otros lugares, han recibido de alguna manera «la migración en herencia».

Para abordar un tema tan crucial, los autores aquí reunidos han movilizado métodos y recursos de diversas disciplinas -historia, geografía, antropología, sociología- jugando con las escalas y los tiempos con el fin de acercarse no a una imagen exhaustiva de la migración en las Américas, lo que sería imposible, sino más bien a la manera en la que el presente y el pasado de las migraciones afectan a las experiencias que viven las poblaciones migrantes y sus descendientes $\mathrm{y}$, en un sentido más amplio, las sociedades de origen y de acogida. Los estudios migratorios, en particular en las Américas, han sido profundamente renovados desde sus orígenes y a veces es complicado querer dar 
coherencia a este fenómeno que hoy en día se puede abordar desde múltiples facetas. Esta es, sin embargo, la ambición del presente dossier. La heterogeneidad buscada de las distintas contribuciones permite dar cuenta de la diversidad de memorias, experiencias y circulaciones, pero también aglutinar trabajos que comparten un enfoque centrado en la persona, el individuo y la experiencia humana, directa o indirecta, de la migración. A través de la correspondencia, los archivos, las entrevistas, las cifras y el terreno se dibuja la figura de los migrantes en movimiento, quienes, a través de sus desplazamientos, huellas y conexiones, confieren su especificidad al continente americano.

4 Elemento fundacional de las Américas, la migración se enmarca también en un sistema global. El paso de una escala a otra permite inscribir los diferentes casos en la historia y la actualidad de la mundialización. Ya se trate de trabajadores pobres, migrantes cualificados, militantes o emprendedores, con trayectorias bien definidas o prácticas de circulación complejas entre regiones y países, los desplazamientos de los migrantes unen a países y zonas diferentes pero cada vez más interconectadas. Desde esta perspectiva, el conjunto de artículos de este dossier -que en su mayoría analizan casos nacionales- permite ver también cómo los itinerarios migratorios dibujan la geografía del continente hasta el punto de que todos sus actores se ven afectados, incluidos los que no migran.

5 Pese a la diversidad de las cuestiones tratadas, los autores coinciden en una serie de temáticas generales que recorren sus escritos. La primera es la memoria viva de la migración, la continuidad de la experiencia vivida más allá del momento de la migración stricto sensu, que se estudia sobre todo a través de la correspondencia, un material que ha experimentado una reciente renovación historiográfica. Los diferentes usos que los migrantes y viajeros hacen de la correspondencia muestran cómo se hacen y deshacen, en el tiempo, las redes transnacionales. Tanto en el análisis de Aubert sobre cómo los misioneros episcopalianos produjeron a través de la escritura y la fotografía una imagen literaria y visual de sus «terrenos» en el sur del continente, de Brasil a Chile, en un doble movimiento de exotización e integración en el proyecto imperial estadounidense, como en el estudio de Da Orden sobre las cartas de familias de migrantes sicilianos en Argentina durante varias generaciones (1910-1980), la correspondencia permite reconstruir la temporalidad de las experiencias migratorias. En el caso de Da Orden vemos cómo la correspondencia tiene varias funciones y se convierte para el historiador en el soporte para estudiar las relaciones de poder en el seno de las familias y la reconfiguración de las relaciones familiares en el contexto migratorio. Venkovits, por su parte, analiza cómo el gobierno de Porfirio Díaz alentó y promocionó la correspondencia y los relatos de viajeros húngaros entre los potenciales migrantes europeos para fomentar su llegada a México en lugar de a Estados Unidos.

6 La memoria de la migración -enmarcada ya sea en un proyecto político o en una estrategia familiar ampliada a la parentela- se expresa no solo a través de la escritura sino también mediante la patrimonialización de los objetos, transmitidos primero dentro de las familias y reunidos luego en museos, como muestra Daniel en el caso de los descendientes de inmigrantes finlandeses, judíos o alemanes en Estados Unidos. Al conceder a los objetos y a los archivos familiares un lugar en los museos étnicos, se les convierte en una institución para el grupo y se inscribe simbólicamente a las comunidades en el país de acogida. Esta etnicidad simbólica, construida por las 
generaciones posteriores, también enmarca la migración en una temporalidad prolongada, multigeneracional, donde se entrelazan historia y memoria.

7 Lo vemos cuando se trata de migración: las idas y venidas en el espacio y en el tiempo son múltiples y complejas. Esto es evidente cuando nos acercamos a la larga historia de las migraciones, pero este vaivén caracteriza también a los casos más contemporáneos que ilustran este dossier. A través del análisis del comportamiento de los migrantes de luto en el Quebec de la década de 2010, Rachedi et al. llegan a la conclusión de que existe una amplia variedad de comportamientos que van desde la voluntad de reproducir de forma idéntica los ritos funerarios de los antepasados a modificar, e incluso inventar, ritos inéditos que permiten a los migrantes y a sus descendientes afrontar el futuro en la sociedad en la que viven.

El segundo tema es el de la experiencia migratoria que, como hemos dicho, constituye un punto de vista reciente en los trabajos sobre migraciones. Diversos actores abordan esta cuestión desde el ángulo del reconocimiento social: los migrantes desean obtener derechos y un estatus acorde con su participación económica o política en la sociedad de acogida. Schaffhauser se interesa por las movilizaciones de los jornaleros agrícolas mexicanos de los años 40 a 60 -los braceros- que en los 2000 se lanzan a reivindicar la jubilación por la que han cotizado y que no se les ha pagado. Sanders analiza la brecha entre migrantes emprendedores y los servicios públicos que en teoría deben ayudarles con su actividad en Nueva York y Filadelfia. Luconi compara la participación política de los migrantes italianos de Argentina y de Estados Unidos en la primera mitad del siglo $\mathrm{XX}$.

9 Las conclusiones de los tres autores son divergentes. Sanders presenta un «balance mediocre» ya que si bien las políticas de acompañamiento de los migrantes emprendedores -símbolo del reconocimiento de su estatus y sus derechos- son positivas para que las empresas se adecúen a las normas locales, la burocracia genera dificultades estructurales que afectan a estas personas. Schaffhauser interpreta la reciente experiencia política de los jubilados braceros como una contribución democrática a la sociedad mexicana contemporánea. Para este autor, las demandas de los braceros, que confían firmemente en que sus derechos serán reconocidos y se movilizan sin descanso para conseguirlo, «reinstitucionalizan» las instituciones mexicanas al obligarles a funcionar como un servicio público, lo que no siempre sucede en la mayoría de los casos en México. Para Luconi, en función de si los migrantes italianos se instalaron en Estados Unidos -ya dominados por los protestantes noreuropeos- o en Argentina donde la sociedad nacional estaba aún por construir- fueron aceptados con más o menos retraso en la arena política, donde pudieron, o no, desempeñar algún papel. En Argentina, la elección del primer presidente de origen italiano en 1890 supuso sin duda ese reconocimiento, que en Estados Unidos fue mucho más tardío.

Un proyecto eminentemente político como fue la emigración voluntaria de los afroamericanos a Haití antes de la abolición de la esclavitud muestra cómo los que se van (y a veces vuelven) y también los que planean irse, pero se quedan, participan de construcciones políticas nacionales complejas como las de Haití y Estados Unidos. Bourhis-Mariotti ilustra este aspecto poco conocido de la historia del abolicionismo en el que la migración -como proyecto o como realidad- constituye una cuestión política, en contrapunto con las tendencias existentes en Estados Unidos en los últimos años de la esclavitud. Para los descendientes de esclavos, la migración voluntaria -a diferencia de los proyectos de emigración de libertos que querían los abolicionistas blancos- es 
una afirmación de libertad y una crítica, en actos, al racismo del régimen político estadounidense.

11 Cohen mueve el foco proyectándolo a lo íntimo y muestra cómo los trabajadores mexicanos sin papeles de un restaurante de Chicago -donde la autora realizó una observación participante- mantienen relaciones sentimentales y familiares cuya condición varía de un lado y de otro de la frontera. La frontera estructura aquí relaciones sentimentales marcadas por la desigualdad de sexo pero también, en el caso de Chicago, por un mestizaje étnico y social (las amantes no pertenecen al grupo y están más instruidas) que para los hombres no tiene consecuencias. Las relaciones asimétricas entre hombres migrantes y mujeres estadounidenses complican las jerarquías de estatus y poder entre migrantes y no-migrantes y vemos cómo la condición de migrante puede reconfigurar hasta las situaciones más personales.

Un tercer tema presente en este dossier permite ver en qué medida la circulación de personas une los espacios -ya sea en el continente americano (Morales, Baby-Collin), entre las Américas y Europa (Gérard y Grediaga, Miret y Córdoba) o entre Asia y las Américas (Essss, Medianu y Sutter)- partiendo de realidades diversas como la movilidad de estudiantes de ingeniería mexicanos o las relaciones con el espacio habitado de colombianos en Barcelona.

13 Para Gérard y Grediaga, que analizan los itinerarios de formación de estudiantes de ingeniería mexicanos durante la segunda mitad del siglo XX y examinan la articulación entre movilidad y circulación de saberes en un mundo globalizado y jerarquizado, la movilidad tiene consecuencias paradójicas. Los autores constatan que la construcción de "cadenas de saber», o dicho de otro modo, de una cooperación privilegiada entre instituciones mexicanas y extranjeras, pese a estar inicialmente ligada a la movilidad de los estudiantes, ha ido reduciendo dicha movilidad de generación en generación. También señalan que las trayectorias de formación se han modificado, creando nuevas relaciones institucionales y nuevos circuitos de movilidad y rompiendo así con ciertos legados.

14 Las transformaciones del espacio son también un efecto de la movilidad de las personas, como apuntan Miret y Córdoba. A partir del discurso y la experiencia biográfica de una veintena de colombianos, estudiantes o emigrantes cualificados llegados a Barcelona en los años 2000, estos autores tratan de entender cómo las experiencias urbanas vividas en el país de acogida repercuten en los cambios de vida en el país de origen. De vuelta a Colombia, estos migrantes adoptan nuevos modos de vida urbanos parecidos a los que han conocido en el extranjero. Por otro lado, Miret y Córdoba lanzan la hipótesis de que la imagen negativa del espacio urbano local, en Colombia, y la representación idealizada y mitificada del espacio urbano europeo podrían haber incitado a estos colombianos a migrar.

15 La diversificación y la creciente complejidad de trayectorias migratorias influye a su vez en los itinerarios y en la instalación en nuevos destinos, tal y como analiza BabyCollin a propósito de un fenómeno migratorio poco conocido como el de los bolivarianos en Estados Unidos. Este autor analiza la importancia de este lugar de destino en el campo migratorio bolivariano y en las vivencias de los migrantes.

Por último, como señalan Esses et al. en el caso de Canadá, la construcción de la percepción de los migrantes está también influida por el tratamiento mediático de las «crisis» migratorias que integran a todos los países en un sistema global de movilidad. En este sistema se incluyen los países de América Central, objeto de estudio del artículo 
de Morales, quien describe su estadounización progresiva tras las revoluciones de la segunda mitad del siglo XX y su integración en la globalización económica, ideológica y política a través de sus migrantes. Ciertamente, estos migrantes son actores alejados de sus sociedades de origen, excluidos, o por lo menos, apartados de sus sistemas sociales, políticos y económicos. Pero son también los proveedores de un maná en forma de mandatos enviados a sus allegados cuya distribución genera recomposiciones sociales y territoriales en la región. Morales cierra así este dossier, relacionando experiencia migratoria individual, movilidad regional, nacional e internacional, y globalización. Para él, al igual que para los autores de los artículos del dossier, el «sujeto migrante» constituye un eslabón clave dentro de las modificaciones políticas, económicas y sociales de América Central.

Partir de la experiencia de los migrantes para actualizar las trayectorias, las redes, los anclajes y las pertenencias complejas permite así dibujar un retrato diferente de las Américas, un continente donde la movilidad estructura profundamente las sociedades y las relaciones entre individuos, familias, colectivos, regiones y países.

\section{NOTAS}

1. Aristide R. Zolberg, A Nation by Design. Immigration Policy in the Fashioning of America, Russel Sage Foundation Books at Harvard University Press, 2008

2. $10^{\circ}$ Coloquio anual del Instituto de las Américas organizado por un equipo de investigadores de la Universidad Paris Diderot: https://sites.google.com/site/colloqueida2012/ .

\section{AUTORES}

\section{FRANÇOISE LESTAGE}

Françoise Lestage est professeur des universités en anthropologie et sociologie à l'Université Paris Diderot, UMR URMIS (IRD-CNRS), où elle est co-responsable de l'axe de recherches « Les reconfigurations des migrations contemporaines ». Depuis septembre 2014, elle est détachée au Ministère des Affaires étrangères pour diriger le Centre d'études mexicaines et centraméricaines (CEMCA), Unité mixte CNRS des instituts français à l'étranger (UMIFRE 16) basée à Mexico.Elle est l'auteur de 3 livres en nom propre (1999, 2008, 2011), 2 livres comme coéditrice au Mexique (2011) et en France (2014), 4 directions de dossiers dans revues classées AERES (2009, 2012, 2013, 2014), 51 articles et chapitres de livres. Ces publications ont porté sur les politiques migratoires au Mexique depuis la fin des années 1990 ; sur les relations inter-ethniques en milieu migrant, sur les défunts dans la vie sociale et familiale des migrants; et sur le lien familial et le cycle de vie.Ses recherches actuelles se développent selon trois axes : la gestion publique des états 
d'affliction des migrants par l'Etat mexicain ; les pratiques et perceptions des « retours » des migrants au Mexique et en Amérique centrale ; les inégalités dans l'accès à la reproduction au Mexique et les circuits de maternité pour autrui.Elle a été membre du conseil scientifique de l'Institut des Amériques, et elle est, ou a été, membre des comités de rédaction des revues Problèmes d'Amérique Latine, Migraciones internacionales, Journal de la Société des Américanistes et Mexican Studies/Estudios Mexicanos.

\section{PAUL SCHOR}

Paul Schor est maître de conférences en histoire et civilisation américaines à l'Université Paris Diderot, UMR LARCA 8225, où il est responsable de l'axe de recherches « Histoire du politique dans le monde anglophone ». Il est l'auteur de Compter et classer. Histoire des catégories de la population dans le recensement américain, 1790-1940, Editions de l'EHESS, 2009, ouvrage récompensé par le Willi Paul Adams Award de l'Organization of American Historians, 2011 (traduction en langue anglaise sous presse à Oxford University Press, prévue courant 2016) et avec Nicolas Barreyre, De l'émancipation à la ségrégation: le Sud des États-Unis après la guerre de Sécession, 1865-1896, PUF, 2009.Il a publié de nombreux articles et chapitre d'ouvrages sur l'histoire des catégories raciales aux États-Unis, sur l'histoire de l'immigration aux États-Unis et sur l'histoire des États-Unis écrite en Europe, notamment Manfred Berg, Isabel Soto et Paul Schor, "The Weight of Words: writing about race in the United States and Europe", The American Historical Review, 119 (3), June 2014, p. 800-808.Ses recherches actuelles portent sur le rôle des experts et travailleurs sociaux dans l'imposition de nouvelles normes de vie quotidienne aux États-Unis au début du vingtième siècle.Il a été membre du conseil scientifique de l'Institut des Amériques et est membre des comités de rédaction des revues Sociétés contemporaines et Transatlantica. 